\title{
13 anos da Coordenação de Pós-graduação POLI-UPE
}

\section{Title: 13 years of POLI-UPE Undergraduate Coordination}

\author{
Alexandre Magno Andrade Maciel \\ Escola Politécnica de Pernambuco \\ Universidade de Pernambuco \\ 50.720-001 - Recife, Brasil \\ amam@ecomp.poli.br
}

\author{
Luis Arturo Gómez Malagón \\ Escola Politécnica de Pernambuco \\ Universidade de Pernambuco \\ 50.720-001 - Recife, Brasil \\ lagomezma@poli.br
}

\author{
Alexandre Duarte Gusmão \\ Escola Politécnica de Pernambuco \\ Universidade de Pernambuco \\ 50.720-001 - Recife, Brasil \\ gusmao.alex@ig.com.br
}

\begin{abstract}
A Coordenação de Pós-Graduação (CPG) da Escola Politécnica de Pernambuco está cumprindo 13 anos de atuação em 2016. Após uma árdua jornada de trabalho de muitos professores, alunos e funcionários, estamos recolhendo os frutos de uma Coordenação de Pós-Graduação mais madura e com visão de futuro.
\end{abstract}

Foi assim que, perante os desafios tecnológicos do século XXI e a necessidade de formação de recursos humanos comprometidos com a sociedade, os professores Béda Barbokébas Jr. e Alexandre Gusmão iniciaram as atividades da CPG em 2002. Ao longo deste tempo foram lançados vários cursos de especialização nas áreas das engenharias, e consolidados outros cursos como Engenharia de Segurança do Trabalho que vem sendo ofertado desde 1985.

A estrutura organizacional da CPG conta com a coordenação setorial com as gerências de pós-graduação (lato sensu) e de pesquisa. No decorrer destes anos tempo, vários coordenadores setoriais e gerentes de pós-graduação e pesquisa atuaram na CPG. Os professores Alexandre Gusmão (2003-2010), Alberto Casado (2011-2012), Arnaldo Cardim (2013), Carmelo Bastos (2014) e Luis Arturo Malagón (2015-2016) desempenharam o papel de coordenador setorial, direcionando os rumos da pós-graduação e da pesquisa da POLI, enquanto os professores Alberto Casado (2010-2011), Emilia Rabbanni (2011), Daniel Cunha (2012), Yeda Povoas (2013), Luis Arturo Malagón (2014) e Alexandre Maciel (20152016) atuarem de maneira a fazer dos cursos de especialização da POLI os mais respeitados no Norte/Nordeste. Cabe ressaltar o papel fundamental dos professores Carmelo Bastos (2007-2014) e Sérgio Campello (2015) e Diego Rativa (2016) na gerência de pesquisa atuando no fortalecimento dos programas de mestrado e de iniciação científica da Escola. Este grupo de professores junto com o apoio técnico de Neusa Galindo e Rita de Cassia fazem parte do sucesso da CPG. A experiência acumulada ao longo destes anos, acompanhando as tendências do mercado local, associada as políticas estruturadoras do pais, fizeram da CPG uma pioneira na formação de recursos humanos qualificados para o mercado.

Hoje, passados treze anos, a CPG conta com um portfólio de mais de 20 cursos de especialização fruto dos esforços dos professores da POLI bem como da administração da escola em viabilizá-los. Nossos cursos contam com uma infraestrutura diferenciada com salas de aula equipadas e climatizadas para oferecer à sociedade as melhores condições no processo de ensino aprendizagem.

Acreditamos que muito foi feito, mas muito ainda estar por vir. Muitos investimentos têm sido realizado a fim ter atingirmos a excelência nos cursos ofertados.

Parabéns, muito sucesso e vida longa à CPG

Um forte abraço, 


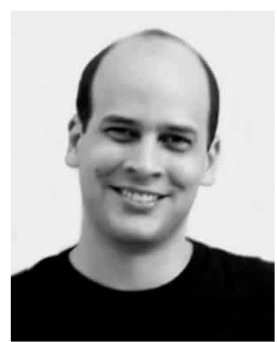

Alexandre Maciel, doutor em Ciência da Computação pela Universidade Federal de Pernambuco (2012), bolsista de Produtividade Desen. Tec. e Extensão Inovadora do $\mathrm{CNPq}$ Nível 2, atualmente é professor adjunto da Universidade de Pernambuco, membro permanente do Mestrado em Engenharia da Computação, Gerente da divisão de Pós-graduação da Escola Politécnica e membro da Câmara de Pós-graduação e Pesquisa da Universidade de Pernambuco.

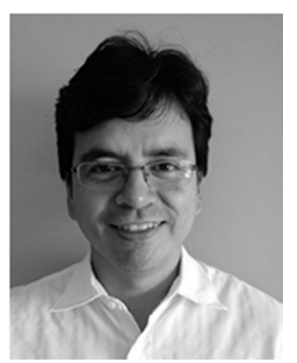

Luis Arturo Gómez Malagón, doutor em Física pela Universidade Federal de Pernambuco (2008), atualmente é professor associado do curso de graduação em Engenharia de Controle e Automação da Universidade de Pernambuco, membro permanente dos cursos de mestrado em Tecnologia da Energia em Engenharia de Sistemas, e coordenador setorial de Pós-Graduação e Pesquisa da Escola Politécnica de Pernambuco.

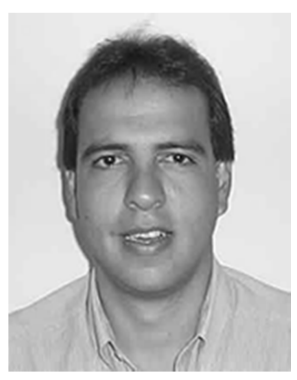

Alexandre Gusmão, doutor em Engenharia Civil pela Pontifícia Universidade Católica do Rio de Janeiro (1999), atualmente é professor associado do curso de Engenharia Civil da Universidade Pernambuco, vice-diretor da Escola Politécnica, membro do Conselho Diretor da Associação Brasileira de Mecânica dos Solos e Engenharia Geotécnica. Tem atuado principalmente nos seguintes temas: resíduos de construção, fundações, estacas, interação solo-estrutura e melhoramento de solos. 